\title{
Effect of Artificial Light Conditions on Local and Systemic Resistance Response of Tobacco to TMV Infection
}

\author{
Zoltán Á. NAGY ${ }^{1,3}$, András JUNG ${ }^{2}$, Zsófia VARGA², \\ György KÁTAY ${ }^{1}$, Attila L. ÁDÁM ${ }^{1 *}$ \\ ${ }^{1}$ Centre for Agricultural Research, Hungarian Academy of Sciences, Plant Protection Institute, 15 Herman Ottó út, Budapest, Hungary; \\ nagy.zoltan@agrar.mta.hu; katay.gyorgy@agrar.mta.hu; adam.attila@agrar.mta.hu (*correspondingauthor) \\ ${ }^{2}$ Szent István University, Technical Department, Faculty of Horticultural Science, 29-43 Villányi út, Budapest, \\ Hungary; jung.andras@kertk.szie.hu; varga.zsofia@kertk.szie.hu \\ ${ }^{3}$ Present address: Mendel University in Brno, Faculty of Forestry and Wood Technology, Phytophthora Research Centre, \\ Department of Forest Protection and Wildlife Management, Zemédělská 3, Brno, Czech Republic
}

\begin{abstract}
Our and literature studies indicated that systemic acquired resistance (SAR) is effectively inducible in greenhouse, and certain artificial light sources cause non-optimal growth of tobacco plants. Therefore, the morphological characteristics, local and systemic resistance response of $N$. tabacum cv. 'Xanthi' $n c$ plants (harbouring $N N$ resistance genes) to tobacco mosaic virus (TMV) infection under three artificial light sources with different spectral distribution were compared with greenhouse conditions. Statistical analysis of data was carried out by R package (R Core Team, 2015). Generally, artificial light sources (especially fluorescent tube and halogen lamp) decreased the local resistance response and caused substantial morphological and developmental differences as compared to greenhouse conditions when plants were kept during their entire life (lifelong experimental regime) under these conditions. On the contrary, no or much less differences were found when plants were transferred from greenhouse to artificial light sources only at six leaf stage (short experimental regime). While induction of SAR frequently decreased TMV lesion size by about 50-60\% under greenhouse conditions, two of the three artificial light sources, fluorescent tube and halogen lamp were substantially and significantly less effective under short experimental regime conditions (25-35\%). A metal halide light source with similarity to sunshine's spectral distribution, however, partially mimicked the effect of greenhouse conditions indicating the importance of light spectrum among other factors in SAR induction and prevention of distorted growth of plants. Consequently, the optimization of the effect of artificial light sources is an important factor in experimental design studying signal transduction and biochemistry of SAR.
\end{abstract}

Keywords: artificial light sources, spectral distribution of light, systemic acquired resistance (SAR), TMV, viral infection

\section{Introduction}

Light is one of the indispensable stimuli for plant growth and development. Light responses are responsible for deetiolation (chloroplast development), flowering and phototropism (Kami et al., 2010). These responses begin with signal perception by phytochromes as red-light photoreceptors and cryptochromes or phototropins as blue-light/UV-A receptors. The signalling downstream of photoreceptors regulates the biosynthesis of a number of phytohormones such as auxins, gibberellins, brassinosteroids, ethylene and cytokinins (Vandenbussche et al., 2005).

Light can influence many other plant responses including resistance to pathogens. In the last decades research has revealed several biochemical, molecular and genetic factors relevant to the development of systemic acquired resistance (SAR) (Shah and Zeier, 2013). More recent efforts have focused on identifying the mobile signal components of SAR responsible for the induction of broad-range resistance in the distant, noninfected, "systemic" leaves (Dempsey and Klessig, 2012; Shah et al., 2014; Nagy et al., 2017). Much less attention was paid to the characterization and optimization of environmental factors involved in the fine regulation of SAR. The first report on tobacco mosaic virus (TMV) induced SAR development and subsequent studies reported $70-80 \%$ inhibition of mean lesion size (or even symptoms invisible to the naked eyes) under greenhouse conditions (Ross, 1961; Vernooij et al., 1994; Ádám and Nagy, 2016). Sometimes the accurate detection of lesion with small diameter (under $1 \mathrm{~mm}$ ) in the plants with SAR was not possible (Pallas et al., 1996). Later studies under artificial but regulated light conditions reported only 25-45\% decrease in the mean of viral (TMV) lesion diameter after SAR induction (Manosalva et al., 2010; Liu et al., 2011a, 2011b; Nagy et al., 2017). 
In order to further characterize and optimize the effect of light quality (spectral distribution) on local and systemic (SAR development) response to TMV infection, we compared in this experiment the effects of three different artificial light sources with greenhouse conditions. Preliminary data suggested that cool white or daylight fluorescent tubes (FT) with shortage of red and far red light constituents, result in dark green and very "compact" plants with short internodes. Therefore, we have chosen an FT light source planned for plant growth. In addition, halogen lamp (HL) and metal-halide lamp (MHL) were also investigated.

\section{Materials and Methods}

\section{Biological material and cultivation conditions}

Nicotiana tabacum cv. 'Xanthi' $n c$ plants grown in a 50-50\% mixture of peat and soil were used in all experiments. Seedlings were planted in their final pot when the first two true leaves reached about $5 \mathrm{~mm}$ in diameter. Induction of SAR started when tobacco plants developed 5-6 fully expanded true leaves in greenhouse (but plants under FT and HL lights produced only four leaves by this time) (Fig. 1). Distance between plants and light sources was set to obtain approximately the same photosynthetically active radiation (PAR) (about 70-80 $\mu$ mole $\left.\mathrm{m}^{-2} \mathrm{~s}^{-1}\right)$. PAR intensity was measured with a BQM-SUM quantum meter (Apogee Instruments, UT, USA). However, the light intensity at summer in the greenhouse was inevitably higher (regardless the shade applied) with daily fluctuation of temperature between minimum $\left(18^{\circ} \mathrm{C}\right)$ and maximum $\left(28^{\circ} \mathrm{C}\right)$. The orientation of the long axis of the greenhouse was SE-NW, in Budapest.

\section{Experimental design}

Two kind of experimental regimes were applied: $i$ ) One part of potted plants was permanently irradiated with different artificial light sources in growth chambers with $10 / 14 \mathrm{~h}$ dark/light photoperiod $\left(20^{\circ} \mathrm{C}\right.$ and $23{ }^{\circ} \mathrm{C}$, respectively) while

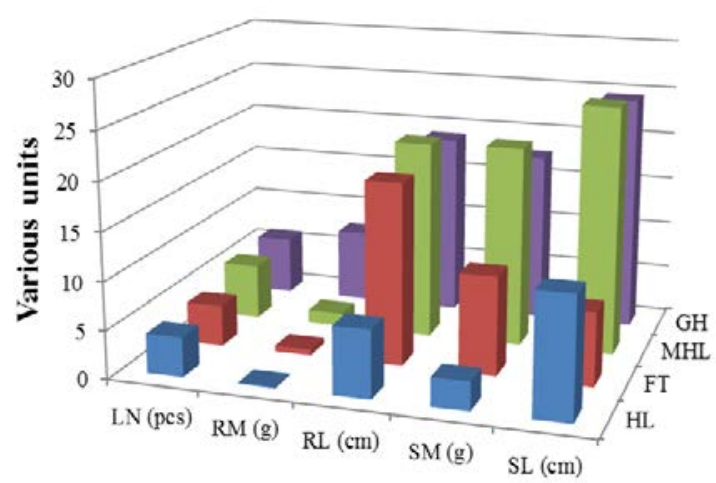

$=\mathrm{HL}$

$\because \mathrm{FT}$

$=\mathrm{MHL}$

$=\mathrm{GH}$

Fig. 1. Effect of spectral distribution of different artificial light sources on growth and development of tobacco (Nicotiana tabacum cv. 'Xanthi' nc). Plants were grown under different light sources, fluorescent tubes (FT), halogen lamp (HL), metal halide lamp (MHL) and greenhouse $(\mathrm{GH})$ conditions during their entire lifetime. Statistical analysis is given in Supplementary Table 1. LN: leaf number (pcs, pieces); RM: root mass (g); RL: root length (cm); SM: shoot mass (g); SL: shoot length $(\mathrm{cm})$ other part of plants remained in the greenhouse during the whole experiment (lifelong experimental regime, LER); ii) in other type of experiment one part of plants was moved from greenhouse to different light sources only at the start of SAR induction (5-6 fully expanded leaves, short experimental regime, SER). During both experimental regimes resistance responses were evaluated. In order to induce SAR, the four bottom-most leaves were inoculated with the U1 strain of TMV as described earlier (Ádám et al., 1990). After one week incubation the development of SAR was detected and evaluated on the leaf level 5-6 by challenge inoculation with TMV. The artificial light sources were as follows: $36 \mathrm{~W}$ fluorescent tubes (FT, Fluora, Osram, Germany), $70 \mathrm{~W}$ halogen lamps (HL, Tungsram, Hungary), $250 \mathrm{~W}$ metal halide lamp (MHL, Arcstream, General Electrics, Hungary). Light spectral measurements were carried out by using a hand-held spectrometer, Qmini (RGB Lasersystems, Kelheim, Germany). The measurement principle of mobile spectrometers is based on diffuse reflectance spectroscopy. It has been widely used in terrestrial spectroscopy and spectral proximal sensing for decades (Milton, 1987). The spectral range from $200 \mathrm{~nm}$ to $1015 \mathrm{~nm}$ with a spectral resolution of $0.327 \mathrm{~nm}$ was measured.

\section{Stastistical analysis}

TMV lesion development was evaluated with ImageJ $1.48 \mathrm{v}$ analysis software as described earlier (Nagy et al., 2016; Nagy et al., 2017). Statistical calculations were carried out with $\mathrm{R}$ ( R Core Team, 2015). For comparison of morphological and developmental characteristics, $t$-test was applied. If the data were not normally distributed, $t$-test was replaced with MannWhitney rank sum test (Supplementary Table 1). The ShapiroWilk $w$-test for normal distribution of lesion size was calculated using function 'shapiro.test' with its default settings. For comparison of sample means, a multiple comparison procedure was used with the R package multcomp (Hothorn et al., 2008). This method tolerates well the heteroscedasticity of samples (unequal variances, non-normal distribution of data, and unbalanced group sizes often present in biological datasets) (Herberich et al., 2010). In order to analyse the difference in dicrease of TMV lesion size due to different light sources during SAR we compared the mean lesion size on SAR induced plants to their corresponding controls. As a standardized effect size, the proportion of lesion size on SAR induced and control plants was calculated. This calculation makes the effect sizes comparable even if the lesion size on control plants grown under different light sources differ. Confidence intervals of these proportions were determined with 5000 bootstrap resampling of the datasets with custom R scripts (Efron, 1979). TMV lesion size distributions of treatments were also calculated with function 'density' of $\mathrm{R}$ with its default settings.

\section{Results and Discussion}

Comparison of the effect of different light sources on the development of plants and local resistance response to TMV infection

First the effect of the different light sources with different spectral distribution and greenhouse $(\mathrm{GH})$ conditions on plant growth and development were compared (Fig. 1 and Supplementary Table 1). In these experiments plants 

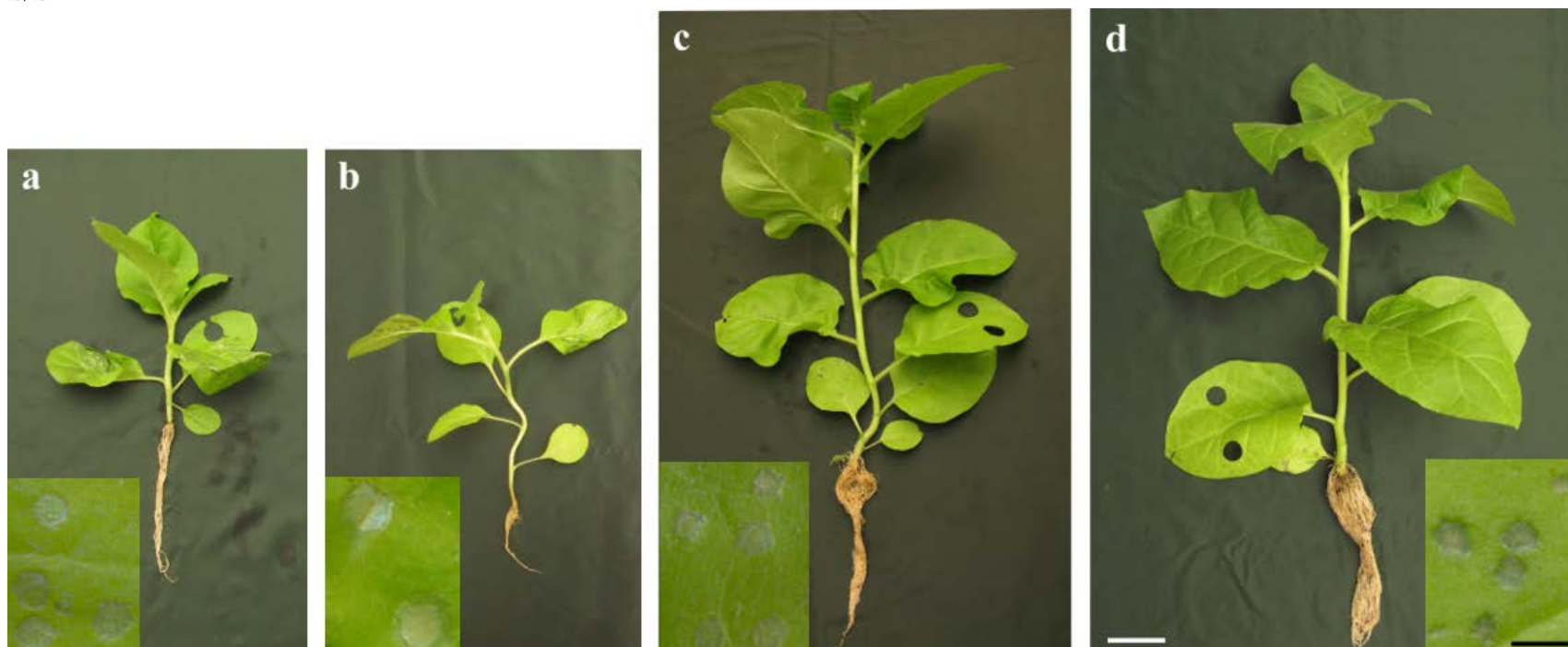

Fig. 2. Plants grown under various light sources in the lifelong experimental regime. Photographs were taken at the end of the experiment. Light sources from a to d: fluorescent tube, halogen lamp, metal halide lamp, greenhouse. Inserts show symptoms of TMV infection on the corresponding plants ( $3 \mathrm{dpi}$ ). White bar: $5 \mathrm{~cm}$, black bar for inserts: $3 \mathrm{~mm}$

developed during their entire lifetime (LER) under different artificial light sources or GH conditions. Greenhouse conditions, however, were not considered as a "control" treatment because other conditions than the light quality and quantity (exposition time, intensity and spectral distribution) may also have been different (see 'Materials and Methods'). When plants were kept under LER, a number of growth and developmental characteristics showed substantial differences (Figs. 1 and 2, Supplementary Table 1). Especially the shoot mass $(\mathrm{SM})$, shoot length (SL) and root mass (RM) were significantly higher and SM/RM ratio was low (2.32 calculated from Supplementary Table 1.) under greenhouse conditions as compared to two artificial light sources (HL and FT). FT resulted in serious stunting effect, dark green leaves with shortened internodes and reduced number of leaves (Figs. 1 and 2). HL light caused retarded growth, smaller root and shoot mass, high SM/RM ratio (24.75), long internodes and decreased number of leaves. HL and FT light showed very different spectral distribution, abundance or shortage in red and far red light, respectively (Supplementary Fig. 1). The abundance of red light putatively acts as stimulant of stem elongation (Tsuchida-Mayama et al., 2010). Far red light, however, blocks germination by promoting abscisic acid synthesis (Piskurewicz et al., 2009). MHL light source compensated well most of the developmental characteristics (especially number of leaves, shoot mass and length) as compared to GH conditions (Figs. 1 and 2, Supplementary Table 1). However, the highest root mass was found under $\mathrm{GH}$ conditions (Fig. 1, Supplementary Table 1). Among spectral distributions of light sources used, MHL was the most similar to sunshine in the greenhouse (Supplementary Fig. 1). These metal halide lamps were successfully applied either in greenhouses or phytotrones (Duke et al., 1975; Tischner and Vida, 1981).

Since the lifelong experimental regime (LER) in two of the three light sources studied was not fully satisfactory in growth and development of tobacco plants (Figs. 1 and 2, Supplementary Table 1), the two growth regimes, LER and SER were compared in the next experiments. Generally, both growth regimes, LER and SER under artificial light sources decreased the local resistance of plants to TMV infection as compared to GH conditions (Fig. 3a, b). As indicated in lesion size distribution curves (Fig. 3a), when plants developed under LER, artificial light sources significantly decreased the local resistance response to TMV infection as compared to $\mathrm{GH}$ conditions (Fig. 2 inserts, Fig. 3c, Supplementary Table 2). HL light source caused the highest increase in mean diameter of TMV lesions $(2.784 \pm 0.072 \mathrm{~mm}$ as compared to $1.197 \pm$ $0.019 \mathrm{~mm}$ of greenhouse plants) and margins of lesions were not well characterized (Fig. $2 b$ insert, Fig. $3 a, c$ and Supplementary Table 2). Less but significant differences were found between $\mathrm{GH}$ and artificial light sources when plants were transferred from $\mathrm{GH}$ to different artificial light sources only after TMV infection for SAR induction (SER) (Fig. 3b and d). There are some fluctuations in lesion size distributions of GH plants of SER and LER experiments (Fig. 3a, b), but the fact that under SER conditions significant differences among different artificial light sources were not detectable (Fig. 3d) suggests the role of the length of irradiation with different light sources. Thus, the differential effect of the two growth regimes on local resistance response indicates the role of putative preformed long-lasting factors in resistance regulated at least in part by different spectral distribution of light sources. For SAR experiments, however, we chose SER conditions. This is explained among others by two main factors: $i$ ) under SER conditions developmental differences with different light sources were not detectable or less pronounced (data not shown) and $i i$ ) the difference in local resistance response to TMV infection under different light sources was also less pronounced (Fig. $3 \mathrm{~b}$ and d).

\section{ofplants}

The effect of different light sources on SAR induction capacity

As compared to $\mathrm{GH}$ conditions, light sources with different spectral distribution influenced not only local resistance response but SAR induction capacity of plants as well (Fig. 4). After induction of SAR, the effect size (proportion of 

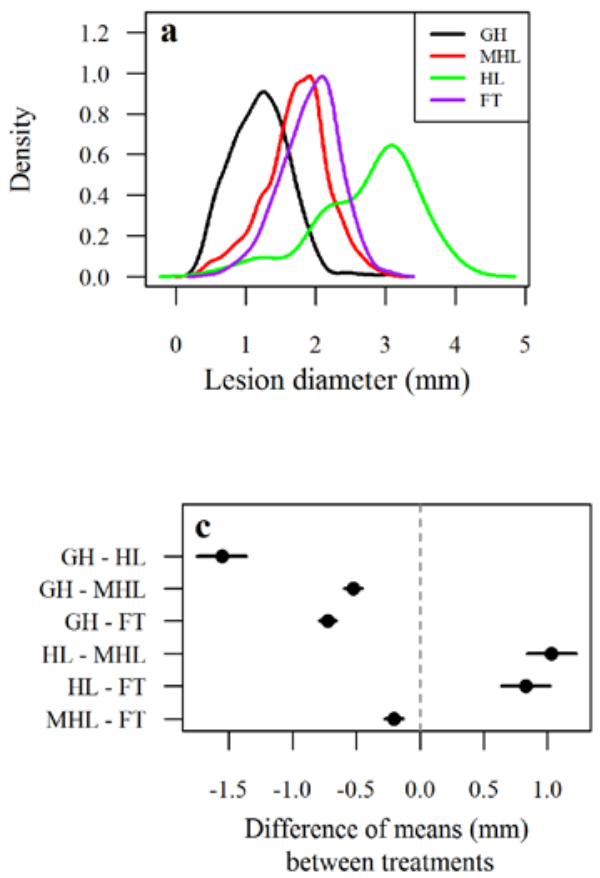
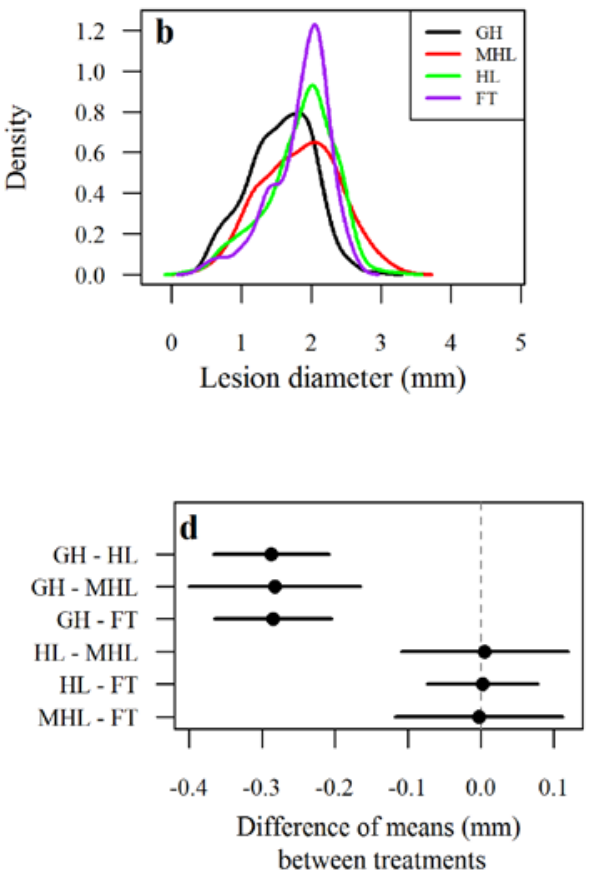

Fig. 3. Effects of different artificial light sources and greenhouse conditions on local resistance response of tobacco plants (Nicotiana tabacum cv. 'Xanthi' nc) to TMV infection. Kernel density estimation of TMV lesion size distribution (a,b) and multiple comparison of means (c,d) on leaf level 5 of plants kept under various light sources for their entire lifetime $(\mathrm{a}, \mathrm{c})$ or moved from greenhouse to different light sources only after TMV inoculation (b,d). Multiple comparisons of mean TMV lesion size were also computed on leaf 5 . Dots represent the difference of the estimated means between treatments. Horizontal segments flank the $95 \%$ confidence intervals. The difference is considered significant if the confidence interval does not contain the 0 , represented by a vertical dashed line. GH: greenhouse; MHL: metal halide lamp; HL: halogen lamp; FT: fluorescent tube
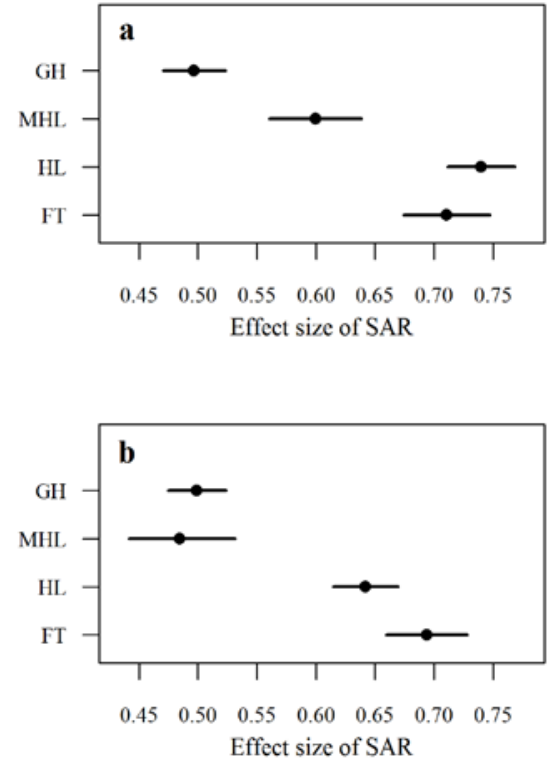

Fig. 4. Comparison of the effect size of systemic acquired resistance (SAR) of Nicotiana tabacum cv. 'Xanthi' nc plants to tobacco mosaic virus (TMV) infection on leaf 5 (a) and 6 (b). Plants were incubated under various light sources during induction of SAR only. Dots: proportion of average TMV lesion size of plants after SAR induction to control. Horizontal segments represent the $95 \%$ confidence interval obtained with 5000 bootstrap resampling. The effect is considered significantly different if the respective confidence intervals do not overlap. GH: greenhouse; MHL: metal halide lamp; HL: halogen lamp; FT: fluorescent tube mean lesion diameter of SAR induced and corresponding control plants) was evaluated in two different leaf level under different light sources. MHL and $\mathrm{GH}$ conditions induced higher degree of SAR response on fifth and sixth leaves (about $40-50 \%$ reduction in lesion size, Supplementary Table 2). As it was predictable from the spectral analysis, GH and MHL lights were relatively close to each other and so was their effect on SAR induction capacity (Fig. $4 \mathrm{a}$ and b). In addition, HL and FT lights had deficiencies in their spectra compared to natural light $(\mathrm{GH})$, and their effects were also reduced (i.e. manifestation of SAR decreased). Thus, bootstrap confidence intervals in Fig. $4 \mathrm{a}$ and b clearly indicate that $\mathrm{GH}$ conditions and $\mathrm{MH}$ light source significantly differ from FT and HL light sources. Despite the fact that under GH conditions lightdependent factors (for example seasonal fluctuation in photoperiod) and other environmental factors than light also can influence SAR induction, the results presented and the spectral similarity of MHL to sunshine (Supplementary Fig. 1) suggest a specific spectral distribution of light that promotes SAR induction.

Besides the present studies on spectrum of light sources, other light dependent factors were studied during SAR induction. For example duration of light radiation after bacterial infiltration influences the quality of signal transduction pathway(s) activation and the strength of SAR development afterwards (Attaran et al., 2009; Liu et al., 2011a). Moreover, lack of light (darkness) can completely inhibit bacterium-induced hypersensitive response and development of SAR and accumulation of salicylic acid (SA) in distant leaves in Arabidopsis (Zeier et al., 2004). In addition, phytochrome signalling also modulates salicylic acid dependent SAR activation in Arabidopsis 
274

(Genoud et al., 2002). However, it is unclear at present and needs further studies whether spectral distribution of light influences SAR development via phytochrome signaling.

\section{Conclusions}

Our results clearly indicate that spectral distribution of light sources influences i) plant growth and development, ii) local resistance response to TMV infection and iii) SAR inducing capacity of tobacco plants. Certain light sources (FT and HL) with unbalanced light spectrum had negative impact on plant growth and development, local resistance response (especially under LER conditions) and SAR induction capacity of plants under SER conditions. However, the most optimal conditions for either plant development or SAR induction capacity were still detectable in the greenhouse. Strong plant responses are especially important features if phenotypes of SAR minus mutant plants or signalling processes are tested. On the other hand, experiments with tobacco draw the attention to optimized growth of plants that could be a more difficult problem with rosette-shaped plants. Therefore, in addition to exact detection and comparison of symptoms' expression after SAR induction (Nagy et al., 2016, 2017), optimization of the effect of artificial light sources is also an important factor in experimental design studying SAR.

\section{Acknowledgements}

This work was supported by National Research Development and Innovation Office, grant NKFIH-K112146 (A.L.Á.). The authors thank Dr. Endre Tóth (Centre for Agricultural Research, Hungarian Academy of Sciences, Plant Protection Institute) for the assistance in light intensity measurements.

\section{Refferences}

Ádám A, Barna B, Farkas T, Király Z (1990). Effect of TMV-induced systemic acquired resistance and removal of the terminal bud on membrane lipids of tobacco leaves. Plant Science 66:173-179.

Ádám AL, Nagy ZÁ (2016). A szisztemikus szerzett rezisztencia szignálátvitele: eredmények és kihívások. [Signal transduction of systemic acquired resistance: results and new challenges]. Növényvédelem 77:435-461.

Attaran E, Zeier TE, Griebel T, Zeier J (2009). Methyl salicylate production and jasmonate signaling are not essential for systemic acquired resistance in Arabidopsis. The Plant Cell 21:954-971.

Dempsey DA, Klessig DF (2012). SOS - too many signals for systemic acquired resistance? Trends in Plant Science 17:538-545.

Duke WB, Hagin RD, Hunt JF, Linscott DL (1975). Metal halide lamps for supplemental lighting in greenhouses: crop response and spectral distribution. Agronomy Journal 67:49-53.

Efron B (1979). Bootstrap methods: another loot at the jackknife. The Annals of Statistics 7:1-26.

Genoud T, Buchala AJ, Chua NH, Métraux JP (2002). Phytochrome signalling modulates the SA perceptive pathway in Arabidopsis. Plant Journal 31:87-95.
Herberich E, Sikorski J, Hothorn T (2010). A robust procedure for comparing multiple means under heteroscedasticity in unbalanced designs. PLoS ONE, 5: e9788. doi: 10.1371/journal.pone.0009788.

Hothorn T, Bretz F, Westfall P (2008). Simultaneous inference in general parametric models. Biometrical Journal 50:346-363.

Kami C, Lorrain S, Hornitschek P, Fankhauser C (2010). Lightregulated plant growth and development. Current Topics in Developmental Biology 91:29-66.

Liu P-P, von Dahl CC, Klessig DF (2011a). The extent to which methyl salicylate is required for signaling systemic acquired resistance is dependent on exposure to light after infection. Plant Physiology 157:2216-2226.

Liu PP, von Dahl CC, Park SW, Klessig DF (2011b). Interconnection between methyl salicylate and lipid-based long distance signaling during the development of systemic acquired resistance in Arabidopsis and tobacco. Plant Physiology 144:1762-1768.

Manosalva PM, Park SW, Forouhar F, Tong L, Fry WE, Klessig DF (2010). Methyl Esterase 1 (StMES1) is required for systemic acquired resistance in potato. Molecular Plant-Microbe Interactions 23:1151-1163.

Milton EJ (1987). Principles of field spectroscopy. Remote Sensing 8:1807-1827.

Nagy ZÁ, Kátay Gy, Gullner G, Ádám AL (2016). Evaluation of TMV lesion formation and timing of signal transduction during induction of systemic acquired resistance (SAR) in tobacco with a computerassisted method. In: Shanker AK, Shanker C (Eds). Biotic and Abiotic Stress - Recent Advances and Future Perspectives. InTech, Rijeka, pp 363-372.

Nagy ZÁ, Kátay Gy, Gullner G, Király L, Ádám AL (2017). Azelaic acid accumulates in phloem exudates of TMV-infected tobacco leaves, but its application does not induce local or systemic resistance against selected viral and bacterial pathogens. Acta Physiologiae Plantarum 39:9.

Pallas JA, Paiva NL, Lamb C, Dixon RA (1996). Tobacco plants epigenetically suppressed in phenylalanine ammonia-lyase expression do not develop systemic acquired resistance in response to infection by tobacco mosaic virus. Plant Journal 10:281-293.

Piskurewicz U, Tureckova V, Lacombe E, Lopez-Molina L (2009). Farred light inhibits germination through DELLA-dependent stimulation of $\mathrm{ABA}$ synthesis and $\mathrm{ABI} 3$ activity. EMBO Journal 28:2259-2271.

R Core Team (2015). R: A language and environment for statistical computing. R Foundation for Statistical Computing, Vienna, Austria. URL: http://www.R-project.org/.

Ross AF (1961). Sytemic acquired resistance induced by localized virus infections in plants. Virology 14:340-358.

Shah J, Chaturvedi R, Chovdhury Z, Venables B, Petros RA (2014). Signaling by small metabolites in systemic acquired resistance. The Plant Journal 79:645-658.

Shah J, Zeier J (2013). Long-distance communication and signal amplification in systemic acquired resistance. Frontiers in Plant Science 4:30.

Tischner T, Vida D (1981). Metal halide lamps with rare earth additives 
for plant growth tests. Tungsram Technical Review 48:1889-1895.

Tsuchida-Mayama T, Sakai T, Hanada A, Uehara Y, Asami T, Yamaguchi $S$ (2010). Role of the phytochrome and cryptochrome signaling pathways in hypocotyl phototropism. Plant Journal 62:653-662.

Vandenbussche F, Verbelen JP, Van Der Straeten D (2005). Of light and length: regulation of hypocotyl growth in Arabidopsis. Bioessays 27:275-284.
Vernooij B, Friedrich L, Morse A, Reist R, Kolditz-Jawhar R, Ward E, Uknes S, Kessmann H, Ryals J (1994). Salicylic acid is not the translocated signal responsible for inducing systemic acquired resistance. Plant Cell 6:959-965.

Zeier J, Pink B, Mueller MJ, Berger S (2004). Light conditions influence specific defence responses in incompatible plant-pathogen interactions: uncoupling systemic resistance from salicylic acid and PR-1 accumulation. Planta 219:673-683. 


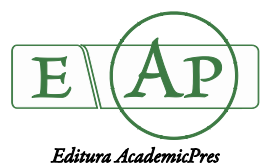

\title{
Effect of Artificial Light Conditions on Local and Systemic Resistance Response of Tobacco to TMV Infection
}

\author{
Zoltán Á. NAGY ${ }^{1,3}$, András JUNG ${ }^{2}$, Zsófia VARGA², \\ György KÁTAY ${ }^{1}$, Attila L. ÁDÁM ${ }^{1 *}$
}

\footnotetext{
${ }^{1}$ Hungarian Academy of Sciences, Plant Protection Institute, Centre for Agricultural Research, 15 Herman Ottó út, Budapest, Hungary; nagy.zoltan@agrar.mta.hu; katay.gyorgy@agrar.mta.hu; adam.attila@agrar.mta.hu ("corresponding author) ${ }^{2}$ Szent István University, Technical Department, Faculty of Horticultural Science, 29-43 Villányi út, Budapest,

Hungary; jung.andras@kertk.szie.hu; varga.zsofia@kertk.szie.hu

${ }^{3}$ Present address: Mendel University in Brno, Faculty of Forestry and Wood Technology, Phytophthora Research Centre,

Department of Forest Protection and Wildlife Management, Zemédèlská 3, Brno, Czech Republic
}

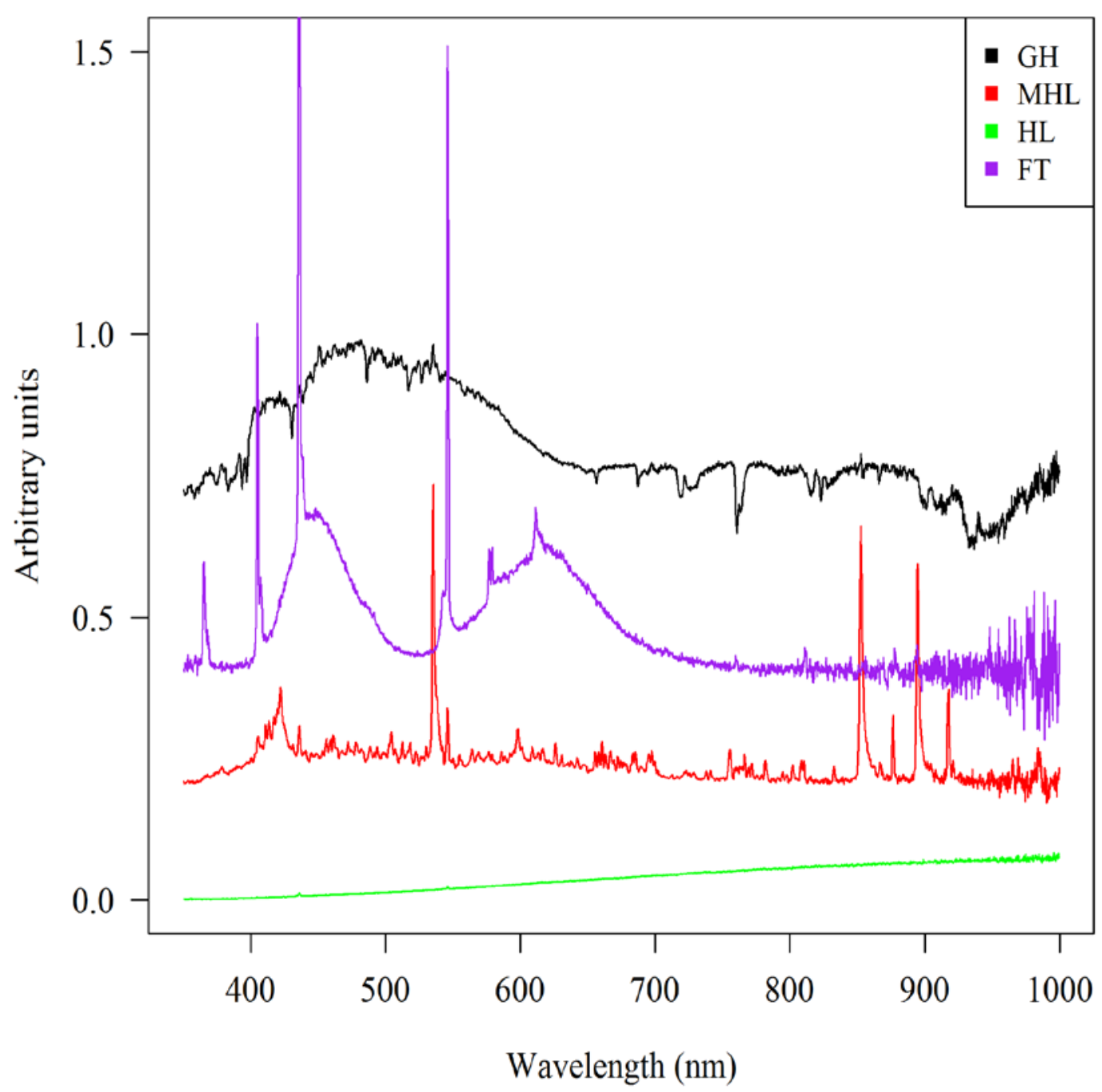

Supplementary Fig. 1. Spectral composition of light sources. For better visualisation of the curves, different constants were added to certain spectra, hence the ordinates are in arbitrary units. GH: greenhouse; HL: halogen lamp; MHL: metal halide lamp; FT: fluorescent tube 
Supplementary Table 1. Morphometric data of experimental plants grown under different artificial light sources and in greenhouse during their entire lifetime

\begin{tabular}{|c|c|c|c|c|c|c|c|}
\hline Character $^{\mathrm{a}}$ & Light source $^{\mathrm{b}}$ & Mean & $\mathrm{SD}^{\mathrm{c}}$ & $\mathrm{n}^{\mathrm{d}}$ & $\mathrm{t}^{\mathrm{e}}$ & $w^{f}$ & $p^{\mathrm{g}}$ \\
\hline LN & $\mathrm{GH}$ & 6.06 & 0.18 & 8 & & - & - \\
\hline LN & MHL & 5.75 & 0.45 & 12 & & 67.5 & 0.084 \\
\hline LN & HL & 4.12 & 0.35 & 8 & & 64.0 & $<0.001^{* * *}$ \\
\hline LN & FT & 4.31 & 0.46 & 8 & & 64.0 & $<0.001^{* * *}$ \\
\hline RL & GH & 19.00 & 4.00 & 3 & - & & - \\
\hline RL & MHL & 20.67 & 10.40 & 3 & 0.259 & & 0.815 \\
\hline RL & HL & 7.00 & 1.00 & 3 & 5.041 & & $0.029^{*}$ \\
\hline $\mathrm{RL}$ & FT & 18.88 & 4.37 & 4 & 0.039 & & 0.970 \\
\hline $\mathrm{RM}$ & GH & 7.60 & 3.60 & 3 & - & & - \\
\hline $\mathrm{RM}$ & MHL & 1.37 & 0.23 & 3 & 4.222 & & $0.050^{*}$ \\
\hline $\mathrm{RM}$ & HL & 0.12 & 0.07 & 3 & 5.088 & & $0.036^{*}$ \\
\hline $\mathrm{RM}$ & FT & 0.63 & 0.22 & 4 & 4.733 & & $0.041^{*}$ \\
\hline SL & GH & 24.50 & 0.50 & 3 & - & & - \\
\hline SL & MHL & 25.75 & 3.52 & 4 & 0.700 & & 0.532 \\
\hline SL & $\mathrm{HL}$ & 12.50 & 3.28 & 3 & 6.267 & & $0.022^{*}$ \\
\hline SL & FT & 7.62 & 1.44 & 4 & 21.804 & & $<0.001^{* * *}$ \\
\hline SM & GH & 17.67 & 1.77 & 3 & - & & - \\
\hline SM & MHL & 20.88 & 6.88 & 3 & 0.784 & & 0.507 \\
\hline SM & HL & 2.97 & 1.22 & 3 & 11.841 & & $<0.001^{* * *}$ \\
\hline SM & FT & 10.29 & 2.93 & 4 & 4.138 & & $0.009^{* *}$ \\
\hline
\end{tabular}

an: leaf number (pieces); RL: root length (cm); RM: root mass (g); SL: shoot length (cm); SM: shoot mass (g).

${ }^{\mathrm{b}} \mathrm{GH}$ : greenhouse; MHL: metal halide lamp; HL: halogen lamp; FT: fluorescent tube. Because of the delayed development of HL and FT plants, LN was determined 10 days earlier (at 5-6 fully expanded leaves of GH plants) than other characters.

'Standard deviation.

${ }^{\mathrm{d}}$ Number of plants.

'Data were compared to GH values in each character in a t test.

Leaf number comparison was done with a Mann-Whitney rank sum test statistic $(w)$ due to non normal data distribution.

${ }^{g}$ Corresponding $p$ values for Mann-Whitney and t tests.

Supplementary Table 2. Lesion sizes in TMV inoculated Nicotiana tabacum cv. 'Xanthi' nc plants after lifelong or short term experimental regimes under various light sources

\begin{tabular}{|c|c|c|c|c|c|c|c|c|c|c|}
\hline \multirow{2}{*}{$\begin{array}{l}\text { Light } \\
\text { type }^{a}\end{array}$} & \multirow{2}{*}{$\begin{array}{l}\text { Treat- } \\
\text { ment }^{\text {b }}\end{array}$} & \multirow{2}{*}{ Leaf level } & \multirow{2}{*}{$\mathrm{n}^{\mathrm{c}}$} & \multicolumn{2}{|c|}{ Lesion diameter $(\mathrm{mm})$} & \multirow{2}{*}{ Norm test $p^{e}$} & \multicolumn{4}{|c|}{ Multiple comparison $^{f}$} \\
\hline & & & & Mean & $S E^{d}$ & & Diff. & Lower CI & Upper CI & $p$ \\
\hline \multicolumn{11}{|c|}{ Lifelong exposition regime (LER) } \\
\hline MHL & Cont. & 5 & 472 & 1.718 & 0.021 & 0.0002 & -0.521 & -0.592 & -0.449 & $<0.001^{*}$ \\
\hline FT & Cont. & 5 & 499 & 1.920 & 0.019 & 0.0041 & -0.723 & -0.790 & -0.655 & $<0.001^{*}$ \\
\hline HL & Cont. & 5 & 78 & 2.784 & 0.072 & 0.0001 & -1.553 & -1.744 & -1.362 & $<0.001^{*}$ \\
\hline $\mathrm{GH}$ & Cont. & 5 & 475 & 1.197 & 0.019 & 0.0001 & - & - & - & - \\
\hline \multicolumn{11}{|c|}{ Short term exposition regime (SER) } \\
\hline MHL & Cont. & 5 & 195 & 1.839 & 0.04 & 0.5182 & -0.282 & -0.399 & -0.165 & $<0.001^{*}$ \\
\hline FT & Cont. & 5 & 408 & 1.842 & 0.021 & $<0.0001$ & -0.285 & -0.364 & -0.205 & $<0.001^{*}$ \\
\hline $\mathrm{HL}$ & Cont. & 5 & 573 & 1.844 & 0.021 & $<0.0001$ & -0.287 & -0.366 & -0.208 & $<0.001^{*}$ \\
\hline $\mathrm{GH}$ & Cont. & 5 & 404 & 1.557 & 0.023 & 0.0028 & - & - & - & - \\
\hline MHL & SAR & 5 & 353 & 1.103 & 0.028 & $<0.0001$ & & & & \\
\hline FT & SAR & 5 & 232 & 1.309 & 0.031 & 0.0043 & & & & \\
\hline HL & SAR & 5 & 615 & 1.365 & 0.022 & $<0.0001$ & & & & \\
\hline $\mathrm{GH}$ & SAR & 5 & 519 & 0.773 & 0.018 & $<0.0001$ & & & & \\
\hline MHL & Cont. & 6 & 57 & 1.714 & 0.055 & 0.3858 & & & & \\
\hline FT & Cont. & 6 & 325 & 1.642 & 0.023 & $<0.0001$ & & & & \\
\hline HL & Cont. & 6 & 400 & 1.884 & 0.022 & $<0.0001$ & & & & \\
\hline $\mathrm{GH}$ & Cont. & 6 & 403 & 1.556 & 0.023 & 0.1981 & & & & \\
\hline MHL & SAR & 6 & 193 & 0.830 & 0.029 & $<0.0001$ & & & & \\
\hline FT & SAR & 6 & 245 & 1.139 & 0.024 & 0.1375 & & & & \\
\hline HL & SAR & 6 & 506 & 1.210 & 0.023 & $<0.0001$ & & & & \\
\hline $\mathrm{GH}$ & SAR & 6 & 410 & 0.776 & 0.016 & $<0.0001$ & & & & \\
\hline
\end{tabular}

a HL: halogen lamp; MHL: metal halide lamp; FT: fluorescent tube; GH: greenhouse.

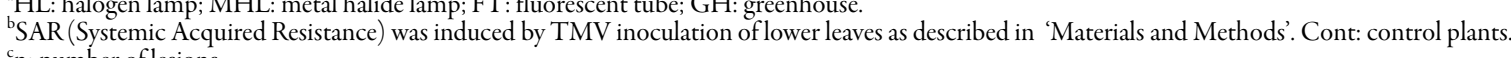

'n: number of lesions.

${ }^{\mathrm{d} S E}$ : standard error of mean lesion diameters.

'Shapiro-Wilk normality test. The $p$ value refers to the probability of the hypothesis that the data indeed originate from normal distribution.

Results of the test for multiple comparison of means. Data in all these four columns refer to a comparison of experimental light treatments (both lifelong and short exposition regimes) and plants kept in greenhouse as a reference. Diff: difference of mean TMV lesion diameter between the reference (GH) plants and those kept in various light sources. Lower and Upper CI: 95\% confidence intervals for each difference of means. An associated $p$ value labelled with ${ }^{*}$ indicates a significant difference of the group means on the level of $\alpha=0.001$. 